\title{
MODEL PREDIKSI KESESUAIAN LAHAN BUDIDAYA TANAMAN PANGAN DENGAN BACKPROPAGATION NEURAL NETWORK (STUDI KASUS: SUB-DAS BENGKULU HILIR)
}

\author{
Ernawati $^{1}$, Desi Andreswari ${ }^{2}$, Tommy Alexander ${ }^{3}$ \\ Program Studi Informatika, Fakultas Teknik, Universitas Bengkulu. \\ Jl. W.R. Supratman Kandang Limun Bengkulu 38371A Indonesia \\ (Telp : 0736-341022; fax: 0736-341022) \\ ${ }^{1}$ alexandertommy10@gmail.com \\ ernawati@unib.ac.id \\ ${ }^{3}$ desi.andreswari@unib.ac.id
}

\begin{abstract}
Abstrak: Selama ini, dalam menentukan jenis budidaya tanaman pangan yang sesuai ditanam pada SubDAS Bengkulu hilir hanya dilakukan berdasarkan pengamatan petani serta dengan membandingkan datadata yang ada di lapangan. Tentu saja cara seperti ini tidak akan mendapatkan hasil yang maksimal. Dalam penelitian ini, Jaringan Syaraf Tiruan (JST) berbasis metode Backpropagation digunakan untuk memberikan informasi yang tepat mengenai tanaman yang cocok ditanam pada sub-DAS Bengkulu Hilir dengan mudah, cepat, dan akurat. Aplikasi ini dibangun dalam bahasa pemrograman PHP dan dirancang dengan Data Flow Diagram (DFD) sedangkan pengembangan sistem dilakukan dengan metode waterfall. Terdapat dua parameter yang diperoleh dari hasil pengujian, yakni nilai Eps (error minimum yang diharapkan) $=0.001$ dan nilai maksimum epoh $=0.8$. Berdasarkan nilai parameter tersebut diperoleh tingkat ketepatan prediksi sebesar $95,8 \%$ dari 24 data pengujian. Hal ini mengindikasikan bahwa metode yag diusulkan cukup efektif dan efisien dalam melakukan prediksi jenis tanaman pangan yang sesuai pada lahan sub-DAS Bengkulu Hilir.

Kata Kunci: Jaringan syaraf tiruan, Backpropagation, Kesesuaian Lahan, Tanaman Pangan, sub-DAS
\end{abstract}

\begin{abstract}
So far, in determining the type of cultivation of suitable food crops planted in the Bengkulu downstream watershed, it is only based on observations of farmers and by comparing the data in the field. Of course this way will not get maximum results. In this study, Artificial Neural Network (ANN) based on Backpropagation method is used to provide precise information about suitable plants planted in the Bengkulu Downstream sub-watershed easily, quickly, and accurately. This application is built in the PHP programming language and is designed with Data Flow Diagrams (DFD) while the system development is done by the waterfall method. There are two parameters obtained from the test results, namely the value of Eps (minimum expected error) $=0.001$ and the maximum value of epoh $=0.8$. Based on these parameter values, a prediction accuracy level of $95.8 \%$ was obtained from 24 test data. This indicates that the proposed method is quite effective and efficient in predicting suitable types of food plants in Bengkulu Hilir sub-watershed land.
\end{abstract}

Keywords: Artificial neural networks, Backpropagation, Land Suitability, Food Plants, sub-watershed

\section{PENDAHULUAN}

Daerah Aliran Sungai (DAS) (catchment, basin, watershed) merupakan daerah dimana semua airnya mengalir ke dalam suatu sungai yang dimaksudkan. Daerah ini umumnya dibatasi oleh batas topografi, yaitu merupakan tempat tertinggi (punggung bukit) sehingga air hujan yang jatuh didalamnya akan selalu menuju tempat hilirnya (bagian yang lebih rendah). Batas ini tidak ditetapkan berdasar air bawah tanah karena permukaan air tanah selalu berubah sesuai dengan musim dan tingkat kegiatan pemakaian. 
Kesesuaian lahan adalah kecocokan suatu lahan untuk penggunaan tertentu, sebagai contoh lahan sesuai untuk irigasi, tambak, pertanian tanaman tahunan atau pertanian tanaman semusim. Kesesuaian lahan untuk tanaman pangan di SubDAS Bengkulu Hilir perlu didukung informasi. Jaringan syaraf tiruan merupakan salah satu representasi buatan otak manusia yang selalu mencoba mensimulasikan proses pembelajaran pada otak manusia. Memprediksi kesesuaian lahan tanaman pangan dapat dilakukan berdasarkan pedoman penilaian kesesuaian lahan untuk komoditas pertanian strategis (Wahyunto, 2016).

Tindakan Pengelolaan Sub-DAS Bengkulu hilir salah satunya adalah penggunaan lahan. Produktivitas tanaman pangan di Sub-DAS tergantung pada kualitas lahan. Saat ini, penentuan jenis budidaya tanaman pangan yang sesuai ditanam pada Sub-DAS masih dilakukan secara manual, yaitu membandingkan data-data yang ada di lapangan serta pengamatan petani sehingga hasil yang didapatkan tidak maksumal, sedangkan untuk analisis lahan membutuhkan waktu, tenaga, dan biaya yang tidak sedikit karena memerlukan 18 parameter kesesuaian lahan. (Anifudin Aziz, 2006)

\section{LANDASAN TEORI}

\section{A. Kesesuaian Lahan}

Evaluasi atau penilaian kesesuaian lahan adalah proses pendugaan tingkat kesesuaian lahan untuk berbagai alternatif penggunaan lahan, dan dalam hal ini ditujukan untuk penggunaan lahan pertanian. Penilaian kesesuaian lahan dapat dilaksanakan secara manual ataupun secara komputerisasi.

\section{B. Peramalan}

Prediksi pada dasarnya merupakan dugaan atau prediksi mengenai terjadinya suatu kejadian atau peristiwa di waktu yang akan datang. Prediksi bisa bersifat kualitatif(tidak berbentuk angka) maupun kuantitatif (berbentuk angka).

\section{Model}

Model adalah penyederhanaan suatu sistem di dunia nyata (real world), sementara sistem adalah mekanisme dimana berbagai macam komponen saling berinteraksi dengan suatu cara tertentu untuk menunjukkan fungsinya di dunia nyata (Handoko, 2005).

\section{Jaringan Syaraf Tiruan}

Jaringan syaraf tiruan (Artificial Neural Network) adalah salah satu bagian dari kecerdasan buatan (Artificial Inteligence). Jaringan syaraf tiruan merupakan salah satu representasi buatan dari otak manusia yang selalu mencoba untuk mensimulasikan proses pembelajaran pada otak manusia. Istilah buatan ini diimplementasikan dengan menggunakan program komputer yang mampu menyelesaikan sejumlah proses perhitungan selama proses pembelajaran.

Pada jaringan syaraf tiruan, neuron - neuron akan dikumpulkan dalam lapisan - lapisan (layer) yang disebut dengan lapisan neuron (neuron layers). Neuron - neuron pada satu lapisan akan dihubungkan dengan lapisan - lapisan sebelum dan sesudahnya. Informasi atau masukan yang diberikan pada jaringan syaraf akan dirambatkan dari lapisan ke lapisan, mulai dari lapisan masukan sampai ke lapisan keluaran melalui lapisan yang lainnya yang disebut dengan lapisan tersembunyi (hidden layer).

\section{E. Backpropagation}

Model jaringan backpropagation merupakan suatu teknik pembelajaran atau pelatihan supervised leaning yang paling banyak digunakan. Metode ini merupakan salah satu metode yang sangat baik dalam menangani masalah pengenalan pola-pola kompleks. Didalam jaringan backpropagation, setiap unit yang berada di lapisan input berhubungan dengan setiap unit yang ada di lapisan tersembunyi.

Setiap unit yang ada di lapisan tersembunyi terhubung dengan setiap unit yang ada di lapisan 
output. Jaringan ini terdiri dari banyak lapisan (multilayer network). Ketika jaringan ini diberikan pola masukan sebagai pola pelatihan, maka pola tersebut menuju unit-unit lapisan tersembunyi untuk selanjutnya diteruskan pada unit-unit dilapisan keluaran. Kemudian unit-unit lapisan keluaran akan memberikan respon sebagai keluaran jaringan syaraf tiruan.

Saat hasil keluaran tidak sesuai dengan yang diharapkan, maka keluaran akan disebarkan mundur (backward) pada lapisan tersembunyi kemudian dari lapisan tersembunyi menuju lapisan masukan. Tahap pelatihan ini merupakan langkah untuk melatih suatu jaringan syaraf tiruan, yaitu dengan cara melakukan perubahan bobot, sedangkan penyelesaian masalah akan dilakukan jika proses pelatihan tersebut telah selesai, fase ini disebut fase pengujian. (Siang, 2004).

\section{METODOLOGI}

\section{Populasi}

Populasi merupakan bagian yang diperlukan pada analisis penelitian ini. Populasi berkaitan dengan seluruh kelompok orang, peristiwa, atau benda yang menjadi pusat perhatian penelitian untuk diteliti (Guritno, 2011). Berdasarkan definisi populasi tersebut, maka populasi yang digunakan dalam penelitian ini adalah analisis tanah atau lahan yang digunakan sebagai data latih dan data uji.

\section{Sampel}

Sampel adalah bagian dari jumlah dan karakteristik yang dimiliki oleh populasi tersebut (Guritno, 2011). Sampel yang digunakan pada penelitian ini adalah analisis kesesuaian lahan pada dua belas tanaman pangan yang berbeda yaitu Buncis (Phaseolus vulgaris), Gandum (Triticum aestivum), Jagung (Zea mays), Kacang hijau (Phaseolus radiatus LINN), Kacang kapri (Pisum sativum), Kacang panjang (Vigna sinesis ENDL), Kacang tanah (Arachis hypogea), Kedelai (Glycine max), Padi sawah irigasi (Oryza sativa), Sorgum (Shorgum bicolor), Ubi jalar (Ipomea batatas), Ubi kayu (Manihot esculenta).

\section{ANALISIS DATA \& PERANCANGAN}

Metode pengembangan sistem yang digunakan dalam penelitian ini ialah menggunakan model Waterfall

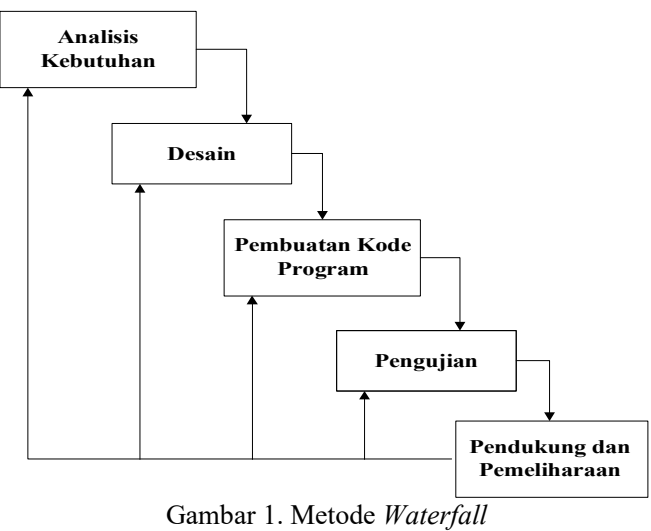

Analisis kebutuhan pada tahap ini, yang dilakukan adalah :

a. Mengumpulkan data primer. Data primer ialah data analisis tanah/lahan pada sub- DAS Bengkulu Hilir yang diambil langsung secara acak pada 3 titik sampel tanah sub-DAS Bengkulu Hilir, Bengkulu Tengah. Untuk setiap titik sampel tanah akan diteliti 17 parameter yang akan menjadi data input untuk sistem prediksi lahan jaringan syaraf tiruan. Parameter akan dibagi menjadi dua pengamatan, yaitu pengamatan langsung dan pengamatan tidak langsung.

1. Pengamatan langsung

Pengamatan langsung adalah pengamatan yang dilakukan dengan mengamati atau meneliti secara langsung 11 dari 18 paramater yang dibutuhkan untuk kesesuaian lahan, yaitu temperatur, tekstur, bahan kasar, kedalaman tanah, kedalaman gambut, kedalaman sulfidik, lereng, bahaya erosi, genangan, batuan dipermukaan, dan singkapan batuan. Pengamatan ini dilakukan oleh laboran 
program studi Ilmu Tanah jurusan Budidaya

Pertanian fakultas Pertanian Universitas

Bengkulu.

2. Pengamatan tidak langsung Pengamatan tidak langsung adalah pengamatan yang dilakukan dengan uji laboratorium untuk mengambil 6 parameter dari 18 parameter yang dibutuhkan untuk kesesuaian lahan, yaitu kapasitas tukar kation (KTK) liat, kejenuhan basa, pH, C-Organik, salinitas, dan alkalinitas. Pengamatan ini dilakukan pada laboratorium program studi Ilmu Tanah jurusan Budidaya Pertanian fakultas Pertanian Universitas Bengkulu.

b. Mengumpulkan data sekunder. Data sekunder adalah data yang didapatkan dari studi pustaka dan observasi. Observasi dilakukan dengan cara mendatangi secara langsung sumber data yaitu,

1. Badan Meteorologi, Klimatologi dan Geofisika untuk mendapatkan data curah hujan yang menjadi satu dari 18 parameter yang dibutuhkan untuk kesesuaian lahan.

2. Dinas Tanaman Pangan Hortikultura dan Perkebunan Provinsi Bengkulu untuk mendapatkan 192 data analisi lahan yang akan digunakan sebagai data latih pada sistem prediksi lahan jaringan syaraf tiruan

c. Menganalisis perangkat lunak dan perangkat keras yang akan digunakan untuk pembuatan sistem prediksi kesesuaian lahan jaringan syaraf tiruan. Berikut ini merupakan perangkat lunak dan perangkat keras yang menjadi sarana pendukung penelitian ini.

Analisis Antarmuka pengguna merupakan tempat untuk pengguna melakukan interaksi maupun komunikasi dengan sistem. Analisis antarmuka pengguna penting dilakukan agar nantinya antarmuka pengguna yang dibuat sesuai dengan tujuan dan fungsi yang diharapkan, serta memudahkan pengguna untukmenjalankan sistem.
Analisis antarmuka dibuat berdasarkan alur penggunaan antarmuka dari pengguna memasukan data uji lahan sampai dengan sistem menghasilkan keluaran berupa prediksi kesesuaian lahan tanaman pangan. Berikut ini garis besar alur antarmuka yang akan dibangun yang dapat dilihat pada Gambar 2. Antarmuka merupakan bagian penting dalam pembuatan sebuah sistem. Perancangan antarmuka dari sistem yang akan dibangun adalah sebagai berikut.

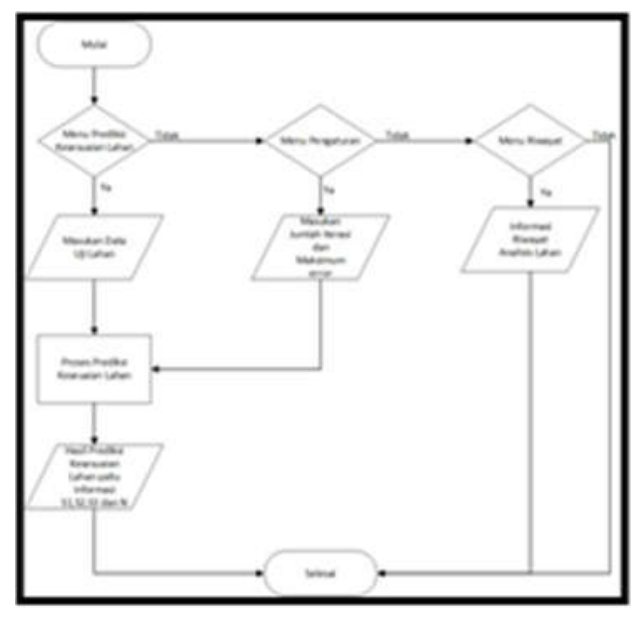

Gambar 2. Diagram Antarmuka Pengguna

Dapat dilihar pada Gambar 2 yang merupakan diagram antarmuka pengguna, disana dapat dilihat bahwa sistem ini terdapat tiga buah menu yaitu menu prediksi kesesuaian lahan, menu informasi dua belas tanaman pangan, dan menu informasi sistem. Berikut ini adalah penjelasan dari ketiga menu tersebut.

a. Menu Prediksi Kesesuaian Lahan

Menu prediksi kesesuaian lahan ini merupakan menu yang berfungsi sebagai tempat untuk user melakukan prediksi kesesuaian lahan dengan backpropagation neural network. Setelah dilakukan proses prediksi, maka sistem akan menampilkan hasil prediksi lahan.

\section{b. Menu Pengaturan}

Menu pengaturan ini memliki fungsi untuk pengguna memasukan jumlah iterasi training an maksimum error yang diharapkan pada proses prediksi. 


\section{c. Menu Riwayat}

Menu riwayat menampilkan riwayat analisis lahan yang telah diprediksi sebelumnya.

\section{d. Halaman Utama}

Halaman utama pada sebuah sistem adalah halaman yang memuat topik utama dari sistem. Halaman utama pada sistem ini muncul pertama kali saat sistem ini dijalankan. Rancangan antarmuka dari sistem temu kembali citra ini dapat dilihat pada Gambar 3 berikut.

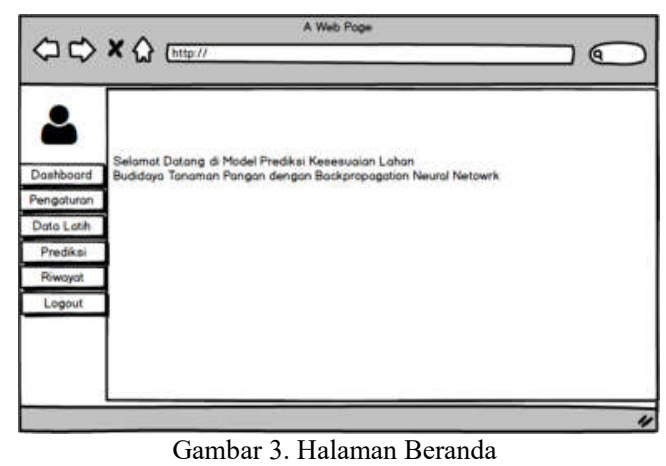

e. Halaman Prediksi Lahan

Halaman prediksi lahan merupakan halaman yang nantinya digunakan pengguna untuk memasukan data lahan uji untuk mendapatkan hasil prediksi kesesuaian lahan. Berikut ini adalah halaman prediksi lahan.

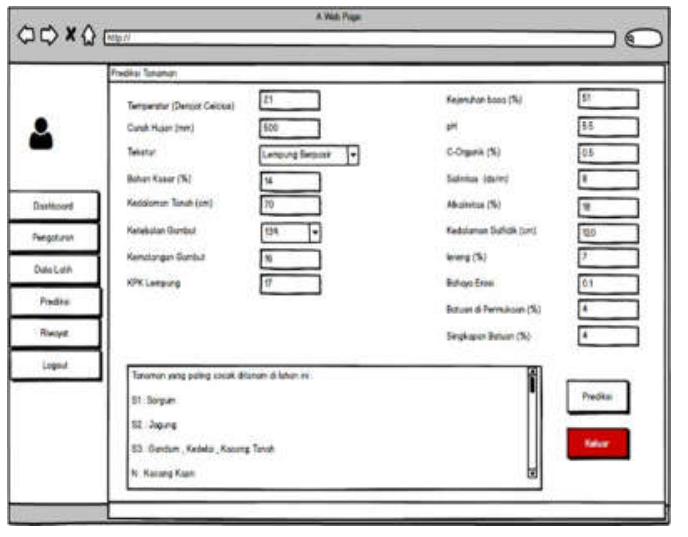

Gambar 4. Halaman Prediksi Lahan

\section{KESIMPULAN}

Berdasarkan penelitian dan pembahasan hasil yang sudah dilakukan, maka terdapat beberapa kesimpulan yang diperoleh dari penelitian ini, diantaranya sebagai berikut :

- Penelitian ini menghasilkan model prediksi kesesuaian lahan budidaya tanaman pangan dengan backpropagation neural network berbasis web dengan nilai learning rate $(\alpha)$ sebesar 0.2, dan menggunakan fungsi aktivasi sigmoid biner.

- Pengujian fungsional pada sistem menggunakan metode black box, telah 100\% berhasil, hal ini ditunjukkan dengan berjalannya semua skenario yang telah dibuat.

- Berdasarkan hasil perhitungan Mean Squared Error (MSE), pada iterasi ke 80 didapatkan angka error yang terkecil.

- Berdasarkan hasil pengujian akurasi sistem, pada 22 kali pengujian berhasil mendapatkan tingkat akurasi sebesar $95,8 \%$

- Dari tiga sampel lahan acak Sub-DAS Bengkulu Hilir, menghasilkan prediksi kesesuaian lahan tanaman pangan padi sawah irigasi pada sampel ke-1 dan ke-3, hasil prediksi sama dengan hasil pengamatan di lapangan yaitu lahan ditanami padi sawah irigasi. Sedangkan pada sampel ke-2 menghasilkan hasil prediksi tanaman pangan kacang hijau, hasil prediksi ini berbeda dengan hasil pengamatan di lapangan yaitu lahan ditanami jagung.

\section{SARAN}

Berdasarkan analisis dan perancangan sistem, implementasi sistem, dan pengujian sistem, maka saran yang dapat diberikan untuk pengembangan penelitian selanjutnya adalah sebagai berikut :

- Model prediksi kesesuaian lahan budidaya tanaman pangan ini dapat dikembangkan lagi untuk melakukan prediksi kesesuaian lahan kelompok tanaman lain seperti, hortikulutra, industri/perkebunan, hijauan pakan ternak, rempah dan obat.

- Untuk pengembangan lebih lanjut diperlukan penambahan jumlah data latih agar meningkatkan akurasi sistem. 


\section{REFERENSI}

[1] Anifudin Aziz, S. B. (2006). Evaluasi Kesesuaian Lahan Untuk Budidaya Tanaman Pangan Menggunakan Jaringan Syaraf Tiruan. Yogyakarta: Universitas Gajah Mada.

[2] Batty, M. a. (Vol. 19). Urban Modelling in Computer Graphic and Geographic Information System Environments. Environment and PlANNing. p. 663-688.

[3] Berger, T. H. (2001). Introduction and Conceptual Overview. Report and Review of International Workshop. Vol.19: p. 663-688.

[4] Bockstael, N. e. (Vol. 14). Ecological Economic Modelling and Valuation of Ecosystems. Ecological Economics. p. 143-159.s

[5] Djaenudin, D. M. (2011). Petunjuk Teknis Evaluasi Lahan Untuk Komoditas Pertanian. Bogor: Balai Besar Litbang Sumberdaya Lahan Pertanian.
[6] Pressman, R. S. (2012). Rekayasa Perangkat Lunak : Pendekatan Praktisi Edisi 7. Yogyakarta: Penerbit Andi.

[7] Riduwan. (2015). Skala Pengukuran Variabel-variabel Penelitian. Bandung: Alfabeta.

[8] Rosa, \&. S. (2013). Rekayasa Perangkat Lunak Terstruktur Dan Berorientasi Objek. Bandung: Informatika Bandung.

[9] Siang, J. J. (2004). Jaringan Syaraf Tiruan \& Pemrogramannya Menggunakan MATLAB. Yogyakarta: Penerbit Andi.

[10] Wahyunto, H. E. (2016). Petunjuk Teknis Pedoman Penilaian Kesesuaian Lahan untuk Komoditas Pertanian Strategis Tingkat Semi Detail Skala 1:50.000. Bogor: Balai Besar Penelitian dan Pengembangan Sumberdaya Lahan Pertanian, Badan Penelitian dan Pengembangan Pertanian 